${ }^{1}$ Afyonkarahisar Devlet Hastanesi Kadın Hastalıkları ve Doğum Polikliniği, Afyonkarahisar, Türkiye e-posta: isaoz80@gmail.com ORCID: 0000-0001-8849-2705

Atıf İçin: ìsa Şükrü ÖZ, Antenatal Takiplerde Saptanan izole Fetal Bağırsak Dilatasyonu, Balıkesir Medical Journal, 2020;4(2): 17-22

Başvuru Tarihi: 19.03.2020 Kabul Tarihi: 15.06.2020 Yayınlanma Tarihi: 23.06.2020

Sorumlu Yazar: İsa Şükrü ÖZ, ${ }^{1}$ Afyonkarahisar Devlet Hastanesi Kadın Hastalıkları ve Doğum Polikliniği, Afyonkarahisar, Türkiye e-posta:

isaoz80@gmail.com

\section{Antenatal Takiplerde Saptanan İzole Fetal Bağırsak Dilatasyonu}

\author{
Isolated Fetal Intestinal Dilatation Detected in Antenatal Follow-up
}

ÖZ

Gebelerin antenatal takiplerinde nadir olarak çeşitli seviyelerde fetal bağırsak genişlemeleri görülebilir. Ultrasonografik olarak fetal bağırsak genişlemesi görünümü fetal bağırsak tıkanıkları, kromozom ve enfeksiyöz bozuklukları ve kistik fibrozis gibi çeşitli durumlar için uyarıcı olabilir. Bu durumlarda doğum sonrası olası bir cerrahi müdahale gerekebilir. Ultrasonografi fetal bağırsak değerlendirilmesinde sınırlı bir etkiye sahiptir. Bu nedenle, antenatal takiplerde fetal barsak dilatasyonunun kazara saptanması, klinisyen için kesin lezyonları ve klinik anlamlı korelasyonlarını tanımlamak ve açıklamak açısından oldukça zordur. Bu nedenle fetal barsak dilatasyonu, farklı doğum sonrası sonuçlarla ilişkili olabilir.

Anahtar Kelimeler: Ultrasonografi; fetüs; bağırsak patolojik bozuklukları

\section{ABSTRACT}

Various levels of fetal bowel enlargement can rarely be seen during antenatal follow-up of pregnant women. The appearance of fetal bowel enlargement can be stimulating for various conditions such as fetal bowel obstruction, chromosome and infectious disorders, cystic fibrosis. In these cases, a possible postpartum surgical intervention may be required. Ultrasonography has a limited effect on fetal gut evaluation. Therefore, accidental detection of fetal bowel dilatation in antenatal follow-up is very difficult for the clinician to identify and explain definitive lesions and clinically significant correlations. Therefore, fetal bowel dilation may be associated with different postnatal outcomes.

Keywords: Ultrasonography; fetus; bowel pathologic disorders 


\section{GiRiş}

Fetal barsak dilatasyonu, çeşitli durumlarla ilişkili olan ve genellikle obstrüktif ve obstrüktif olmayan tiplere ayrılan nadir bir bulgudur (1). Çoğu durumda fetal prenatal bağırsak dilatasyonu genellikle bağırsak tıkanıklı̆ını gösterir. Obstrüktif tipin ayırıcı tanısı geniştir. Bu durum genellikle kistik fibroz, mekonyum ileus, bağırsak atrezisi, imperfore anüs ve volvulusu içerir $(2,3)$. Obstrüktif olmayan bağırsak dilatasyonu nadir görülen bir durumdur. Konjenital klorürür diyaresi, hirschsprung hastalığı, konjenital psödo-konstrüksiyon ve mikrovillus inklüzyon hastalığı durumlarında karşımıza çıkabilir. Prenatal tanı zordur ve yaygın dilate barsak ilmekleri, polihidramnios ve ekojenik bağırsaklardan oluşabilir $(4,5)$. Genel olarak fetal barsak dilatasyonu, en az $15 \mathrm{~mm}$ uzunluğunda veya 7 mm çapında ölçümü yapılan sıvı dolu bağırsak ilmekleri ile karakterizedir (6). Dilate fetal bağırsağın ultrasonografik görüntüsü, bağırsağın mekanik veya fonksiyonel tıkanıklığının bir işaretidir.Ve prevalansı altta yatan duruma bağı olacaktır. Fetal bağırsak dilatasyonunun etyolojisinin tespiti zordur. İkinci trimesterin sonuna kadar bazı tıkanıklar görülmeyebilir (7). Ultrasonografik görüntüleme ile genişlemiş ince bağırsak ilmekleri ve kolon arasındaki farkı tanımlamak, tıkanıklık sayısının ve tıkanma yerinin kesin olarak tanımlanması kadar zordur (8). Bu nedenle fetal barsak dilatasyonu, doğum öncesi yönetimi ve ebeveyn danışmanlığını sorunlu hale getiren, farklı doğum sonrası sonuçlarla ilişkili olabilen bir durumdur.

\section{OLGU SUNUMU}

İkinci gebeliğini yaşayan 31 yaşındaki hasta ilk doğumunu normal vajinal yolla gerçekleştirmiş olup daha önceki gebeliğinde herhangi bir obstetrik patolojiye rastlanmadı. Eşi ile arasında herhangi bir akrabalık yoktu. Hastanın ek hastalığı yoktu. 12. Gebelik haftasında yapılan ikili tarama testinde özellik yoktu. Gebe rutin antenatal kontrolleri için geldiğinde yapılan fetal ultrasonografide 18. gebelik haftasıyla uyumlu fetal ölçümleri bulunan, amnion sıvı miktarı normal sınırlarda olan bir görünüm izlendi. Ayrıca fetal bağırsaklarda şüpheli bir dilatasyon izlendi fakat dilatasyon açısından net bir karara varılamadı. Hastaya 23. gebelik haftasında fetal anomali taraması yapıldı. Anomali taraması sırasında yapılan ultrasonografide $16 \mathrm{~mm}$ ye ulaşan fetal intestinal genişleme alanları izlendi (Resim 1). Bu anomali haftalık olarak izlendi ve fetal genişleme alanları haftalık olarak boyutta aşamalı bir artış gösterdi. Aynı şekilde amniyotik sıvıda da artış izlendi ve 33. haftada hastaya fetal akciğer olgunlaşması yapıldı. 33. haftada intestinal genişleme $21 \mathrm{~mm}$ ye ulaştı (Resim 2). Olgu Çocuk Cerrahisi Bölümü ile tartışıldı ve 37. haftada elektif sezaryen planlandı. 37. haftada amniotik sıvıda polihidroamnios görünümü ve fetal dilate bağırsaklar izlendi (Resim 3). 


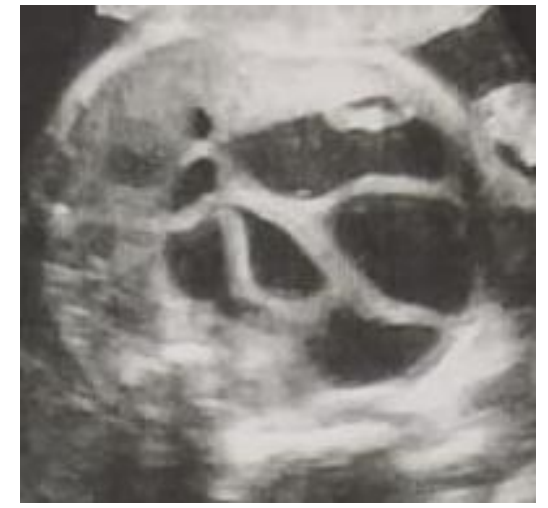

Resim 1. 23. Gebelik haftası dilate bağırsaklar

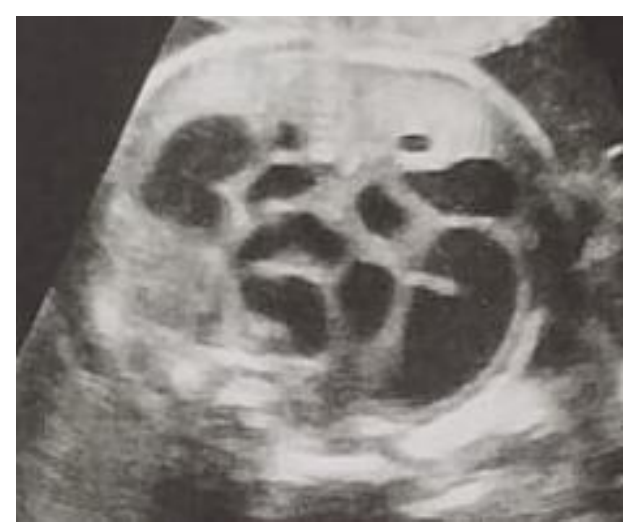

Resim 2. 33. Gebelik haftası

Fetal barsaklar

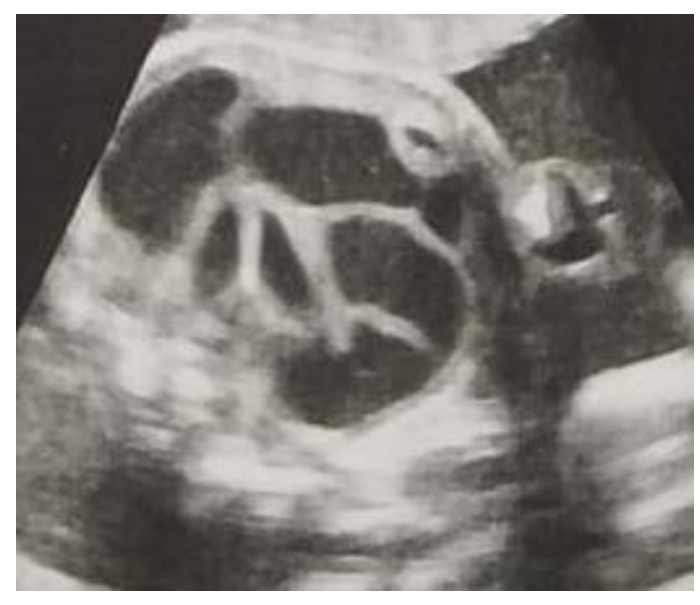

Resim 3. 37. Gebelik Haftası Fetal bağırsak görünümü

37. gebelik haftasında sezaryen yapıldı. Sonuç, ilk dakikada 9, beşinci sırada 10 apgar skoru ile $2849 \mathrm{gr}$ ağırlığında bir kız bebek dünyaya geldi. Yenidoğana yapılan fizik muayenede hafif abdominal distansiyon izlendi. Anal delik, farinks ve alt özofagusta tıkanıklık izlenmedi. Zayıf mide içeriği ve geçirgen bir rektum görüldü ve yenidoğan yoğun bakım ünitesine nazogastrik tüp ile transfer gerçekleşti. Karın distansiyonunun kötüleşmesi ilk saatlerde belirgindi ve stimülasyondan sonra bile dışkı geçişi izlenmedi. Yaşamın 12. saatinde cerrahi değerlendirme için cerrahi yenidoğan ünitesine transfer edildi. Burada yapılan lavman uygulamaları etkisiz kaldı. Çekilen batın grafisinde muhtemelen alt bağırsak atrezisini gösteren genişlemelerle birlikte hava sıvı sevileri izlendi. Ardından laparotomi kararı alındı. Laparotomide ileumun alt kısmının viskid mekonyum ve mikrokolon ile tam tıkanması görüldü. $8 \mathrm{~cm}$ ileum rezeksiyonu yapıldı ve ileostomi uygulandı. Yaşamın 10. gününde oral beslenmenin tolere edilmesiyle yaşamın 15. gününde hasta taburcu edildi.

Bildirilen vakada, anatomik olarak normal büyüyen bir fetüste izole fetal bağırsak dilatasyonu görüldü. Takip ultrason muayeneleri ile yapıldı. Bağırsak görünümü ve perforasyon, asit, mekonyum 
peritoniti veya mekonyum psödokistleri gibi ilişkili komplikasyonlar haftalık olarak takip edildi, ayrıca fetal büyüme ve amniyotik sıvı hacmi kayıt altına alındı.

\section{TARTIŞMA}

Antenatal olarak dilate barsak döngülerinin varlığı fetal barsak tıkanıklı̆ını gösterir. Yenidoğan bağırsak tıkanıklığı yaklaşık 1/2000 canlı doğumda ortaya çıkar (8).

Ruiz ve ark. (9) fetal ultrasonografide anormal bağırsak görünümünün neonatal sonuçlarını değerlendirmiş ve inatçı hiperekojenik bağırsakları olan 9 fetüste \%33' ünde mekonyum peritonit veya mekonyum ileus saptamışlardır. 12 vakada \%66,7'sinde, yaygın bağırsak atrezisi görmüşlerdir.

Fetal bağırsak dilatasyonu olanlarda en sık görülen otozomal resesif hastalık kistik fibrozistir. Kistik fibrozis, olgularının \%15-20'sinde erken yenidoğan döneminde mekonyum ileus olarak kendini gösterir. Ekzokrin bezlerden karakteristik viskoz ve dehidrate sekresyonlar, bağırsak, solunum yolları ve pankreatik kanalların tıkanmasına neden olur (10).

Fetal bağırsak dilatasyonu görülenlerde izlenen diğer anomaliler jejunal ve ileal atrezilerdir. $\mathrm{Bu}$ anomalilerin gebeliğin erken evrelerinde mezenterik kan akışının kesilmesi sonucu olduğu düşünülür. Vasokonstriktif ilaçların maternal kullanımı, kalıtsal trombofili ve vasküler kan akışının bozulmasına neden olan fetal malformasyonlar patogenezde rol oynayabilir (11). Ağırlıklı olarak sporadik olmasına rağmen kalıtsal jejunoileal atrezi vakaları bildirilmiştir. Bu da genetik etiyolojiyi düşündürmektedir (12).

Fetal bağırsak dilatasyonu görülenlerde amniyotik sıvı hacmi proksimal tıkanıklıklarda daha yüksektir. Genişlemiş bir mide ve polihidramnios varlığı daha çok jejunal atrezi olmakla birlikte ileal atreziyi de düşündürebilir (13). Bizim vakamızda da polihidroaminios durumu görülmüştür. Kolon tıkandığında, genel olarak bağırsak dilatasyonu görülmez, çünkü sıvı yukarı akımı ile ince bağırsakta ve kolon döngülerinde emilir.

Fetal bağırsak dilatasyonu görülenlerde çok nadir görülen bir diğer durum ise mikrovillous inklüzyon hastalığıdır ve bu durum bağırsağın ölümcül bir hastalığıdır. Mikroorganizmaların enterositler üzerindeki kısmi veya total atrofisine bağlı olarak, yenidoğanlarda yaşamın ilk birkaç gününde uzamış sulu ishaller görülebilir. Bu durum zorunlu olarak dehidrasyon, metabolik ve elektrolit anormallikleri, enfeksiyonlar ve komplikasyonlarla ilişkilidir. Ölüm kolestatik karaciğer hastalığından veya sepsisinden kaynaklanır (14). Bizim vakamızda bu durumlar izlenmedi.

Yapılan başka bir çalışmada; fetustaki bağırsak anormalliklerinin çeşitli ultrasonografik bulgularla kendini gösterdikleri ve lezyonların doğru tahmininin zorlaştırdığı bildirilmiştir. Aynı 
çalışmada prenatal ultrasonografinin kalın bağırsak lezyonlarını tespit etme duyarlıı̆̆ı zayıf olmasına rağmen, ince bağırsak lezyonlarının saptanmasında \%100 hassas olduğu üzerinde durulmuş ve prenatal ultrasonografide şüpheli bağırsak anormallikleri olan tüm fetüslerde kistik fibrozis düşünülmelidir denmiştir (15).

Sonuç olarak; fetal bağırsak dilatasyonu görülen yeni doğanlarda, bağırsak tıkanıklığı, tıkanıklığın seviyesine ve derecesine bağı olarak sunumda farklı varyasyonlara sahip olabilir. Bu durumlardan bazıları doğum öncesi teşhis edilebilir. Cerrahi olarak düzeltilebilir anomalilerin doğum öncesi tespiti, erken resüsitasyon ve hızlı cerrahi müdahale ile planlı bir doğum yapılmasına izin vererek perinatal morbidite ve mortaliteyi ideal olarak azaltacaktır.

\section{KAYNAKLAR}

1. Colombani $M$, Ferry $M$, Toga $C$, et al. Magnetic resonance imaging in the prenatal diagnosis of congenital diarrhea. Ultrasound Obstet Gynecol 2010;35:560-565

2. Richards C, Holmes SJ. Intestinal dilatation in the fetus. Arch Dis Child Fetal Neonatal Ed 1995.72:135-138

3. Shawis R, Antao B. Prenatal bowel dilatation and the subsequent post-natal management. Early Hum Dev 2006,.5thed Philadelphia 82:297-30

4. Bronshtein M, Blazer S, Zimmer E. Gastrointestinal tract. In: Callen 5thed Philadelphia PW (ed). Ultrasonography in Obstetrics and Gynecology.PA: Elsevier Saunders; 2008.587-639

5. Ruemmele FM, Schmitz J, Goulet O. Microvillous inclusion disease(microvillous atrophy). Orphanet J Rare Dis 2006; 1:22

6. D. A. Nyberg, L. A. Mack, R. M. Patten, and D. R. Cyr, "Fetal bowel. Normal sonographic findings," Journal of Ultrasound in Medicine,1987. vol. 6, no. 1, pp. 3-6.

7. A. Couture, "Fetal gastrointestinal tract: US and MR," in Gastrointestinal Tract Sonography in Fetuses and Children, Medical Radiology, 2008.1st edition, Springer, Berlin, pp. 1-84

8. R. John, F. D'Antonio, A. Khalil, S. Bradley, and S. Giuliani, "Diagnostic accuracy of prenatal ultrasound in identifying jejunal and ileal atresia," Fetal Diagnosis and Therapy, 2015.vol. 38, no. 2 , pp. $142-146$

9. Ruiz MJ, Thatch KA, Fisher JC, et al. Neonatal outcomes associated with intestinal abnormalities diagnosed by fetal ultrasound. J Pediatr Surg 2009;44:71-4

10. Rennie JM, Roberton NRC. Textbook of neonatology. 3rd edn. Philadelphia: Pennsylvania, USA: Churchill Livingstone, 1999. Cystic Fibrosis p.758-759 Gastrointestinal disorders Part 3. Newel SJ. Ch.31 Gastroenterology 
11. S. M. Johnson and R. L. Meyers, "Inherited thrombophilia: a possible cause of in utero vascular thrombosis in children with intestinal atresia," Journal of Pediatric Surgery, 2001.vol. 36, no. 8 , pp. 1146-1149,

12. J. H. Seashore, F. S. Collins, R. I. Markowitz, and M. R. Seashore, "Familial apple peel jejunal atresia: surgical, genetic, and radiographic aspects," Pediatrics, 1987.vol. 80, no. 4, pp. 540544.

13. J. R. Wax, T. Hamilton, A. Cartin, J. Dudley, M. G. Pinette, and J. Blackstone, "Congenital jejunal and ileal atresia: natural prenatal sonographic history and association with neonatal outcome," Journal of Ultrasound in Medicine, 2006. vol. 25, no. 3, pp. 337-342.

14. Phillips AD, Schmitz J. Familial microvillous atrophy: a clinicopatho-logical survey of 23 cases. J Pediatr Gastroenterol Nutr 1992; 14:380-39

15. Corteville JE,Gray DL,Langer JC. Bowel abnormalities in the fetus--correlation of prenatal ultrasonographic findings with outcome. American Journal of Obstetrics and Gynecology, 1996; 175(3 Pt 1):724-729 